\title{
Unilateral Minimally Invasive Posterior Lumbar Interbody Fusion (Unilateral Micro-PLIF) for Degenerative Spondylolisthesis: Surgical Technique
}

\author{
Shigeru Kobayashi \\ Department of Orthopaedics and Rehabilitation Medicine, \\ Faculty of Medical Sciences, The University of Fukui, Fukui, \\ Research and Education Program for Life Science \\ The University of Fukui, Fukui \\ Japan
}

\section{Introduction}

Degenerative spondylolisthesis has long been recognized as a cause of chronic low back pain and sciatica. Extensive anatonmical and embryological studies have not fully explained the cause of this painful condition. The mechanism of pain in degenerative spondylolisthesis has been confirmed by demonstrating the disc lesion pre-operatively by X-rays and MR imaging followed by surgical treatment in which the abnormal disc is totally removed and replaced with bone grafts to effect an interbody fusion. Ralph Cloward first performed the posterior lumbar interbody fusion (PLIF) in 1940 in Hawaii.(1952, 1953, 1981, 1985) . Over the last decade, PLIF has become a popular technique for achieving interbody fusion. The development of pedicle screw fixation system is significant in the history of PLIF. PLIF with pedicle screw systems have apperently improved the rate of arthrodesis (Bridwel et al., 1993, Zdeblick et al., 1993, Yvon et al., 1994, Fischgrund et al., 1997). However, the result of exposure technique can be ischemic necrosis induced by forceful retraction of the paraspinal muscles and postoperative low back pain. The first percutaneous screw placement technique was reported by Magerl (1982) and involved the use of external fixators. The development of technology for minimum invasive placement of rods and pedicle screws was driven by concerns over the amount of paraspinal muscle retraction required in the open approaches. Forley (2001) made a significant contribution to resolving this dilemma with his invention of instruments and a technique to pass rods in a minimally traumatic fashion using an arcbased system called Sextant (Medtronic). The percutaneous pedicle screw system have served as adjuvants in the development of minimally invasive PLIF. And also, interbody spacers have far more better results in term of disc height maintenance and in direct neural decompression than bone grafts alone. Various radiolucent interbody spacers, such as carbon cages (Brantigan \& Steffee, 1993), and polyetheretherketone (PEEK) interbody spacers (Park \& Foley, 2008), are wide and long and provide a large surface area for fusion and generous reconstruction of collapsed disc spacers on the use of interbody spacers for 
PLIF. The graft bone material in the interbody spacers mainly consists of autologous bone which is harvested from the ilium, local bone acquired by posterior decompression and artificial bone, such as hydroxyapetite and $\beta$-tricalcium phosphate ( $\beta$-TCP). The use of local bone and artificial bone has the advantage of avoiding the necessity to harvest from iliac bone, and this advantage is connected with less operating time, blood loss and no postoperative iliac pain. Interbody spacer far better results in term of disc height maintenance, preventing of collapse and indirect neural decompression than bone grafts alone. The first to report the unilateral approach for bilateral spinal canal decompression were Young et al. (1988). Development of this surgical corridor requires the removal of bone from the ipsilateral spinolaminar junction. Tubular access to the lumbar disc was first reported by Faubert and Caspar (1991) and this led the way for the development of tubular retractor systems. The microscope is then utilized to visualize across the midline, and access is achieved to the contralateral recess of the spinal canal (Takeno, et al., 2010). With advances in minimal access technology using operating microscope, PLIF can now be performed through a minimally invasive, unilateral approach, providing an adequate decompression and circumferential fusion, and avoid many of the disadvantages of the traditional posterior open approach. In this report the authors present a surgical technique and clinical outcomes of the unilateral minimally invasive posterior lumbar interbody fusion (unilateral micro-PLIF) for degenerative spondylolisthesis.

\section{Surgical technique}

Following induction of general anesthesia, the patients were positioned prone on a radiolucent table. Reduction of the abdominal pressure is necessary to decrease the blood loss. Before prepping the patient, lateral and anteroposterior C-arm fluoroscopic images were obtained to ensure that the pedicles could be adequately visualised prior to starting the operation.

\subsection{Skin incision}

Surgical access for interbody fusion was obtained under operating microscope using Casper retractor (Aesculap) and a self-retaining retractor of PLIF system (Codman). The approach of unilateral micro-PLIF can be performed from the side that was most symptomatic. An 3 $\mathrm{cm}$. to $5 \mathrm{~cm}$ transverse or longitudinal skin incision is used for 1 level operation (Fig.1A). The subcutaneous fat is incised from lumbosacral fascia and performed the slightly arcuate fascial incision $1.5 \mathrm{~cm}$ from midline (Fig.1B). The median edge of the fascial incision is dissected, bluntly, back to the midline with the aid of surgical forceps and a small raspatory or scissors, and held back with two holding sutures. The midline structures can be shown more easily from the inside. It is important not to release the paravertbral muscles from spinous process subperiosteally and the periosteal membrane of lateral surface on the spinous process should carefully preserved to prevent the blood loss. The paramedian incision later makes uninterrupted suturing of the fascia easier. With a small raspatory, the musculature is detached bluntly from the midline structures up to the arches. In order to unintentionally not go beyond the midline, the detachment should always begin on the lateral surface of the cranial spinous process (in the lower one third) and should be carried out strictly vertically along the bone. The deep anatomical situation is palpated with the finger. Orientation on the position, course, with of the arches, position of the articular 
portions and width of the interlaminar space is thus provided (Fig.1C). At the same time, the distance between the skin surface and the upper edge of the arch is determined using the index finger, so that the appropriated Casper retractor is selected. The musculature is vigorously pulled away about $2 \mathrm{~cm}$ in the lateral direction with the fluted introducer. The Casper retractor is introduced via the surgical hook as near vertically as possible and the interlaminal space is exposed widely, enough to see the facet (Fig.1D). At this stage, X-ray control is taken to confirm the disc level. Under microscope, the ligamentum fluvum is cleared carefully of fat, connective tissue or muscle fiber residues which are still attached to it with a dissection swab by pushing away in the lateral direction. If necessary, these structures are coagulated bipolarly and removed with a rongeur to clearly expose the ligamentum fluvum prior to incision.

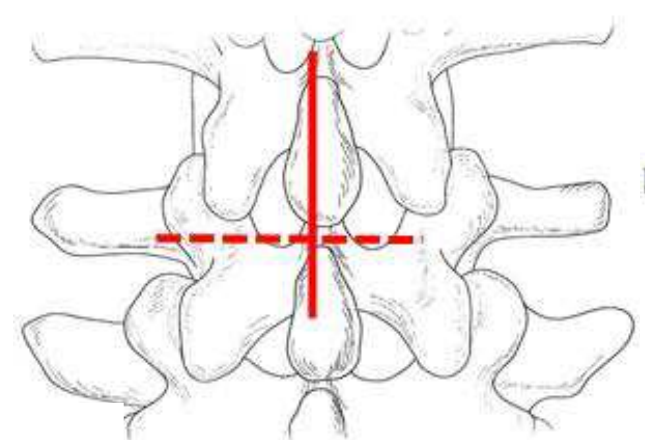

A.

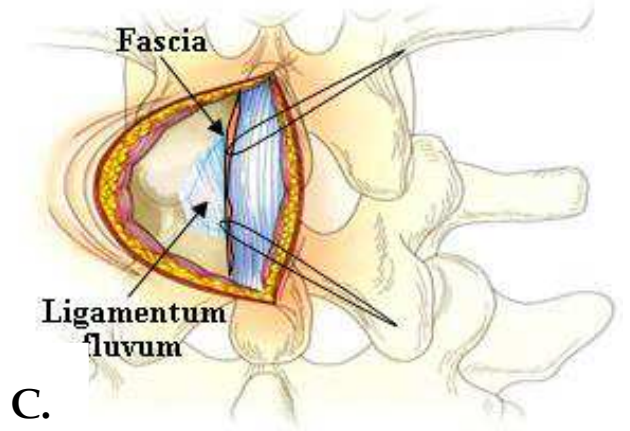

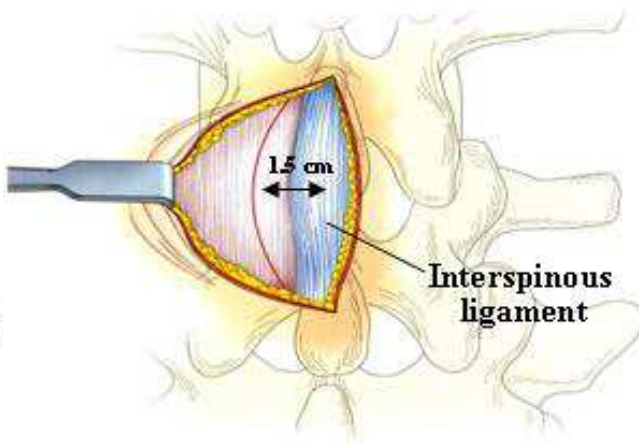

B.

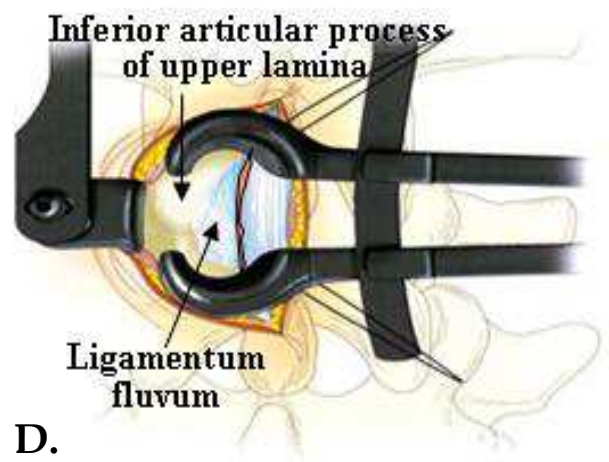

Fig. 1. A. Longitudinal or transverse incisions $(3-5 \mathrm{~cm})$ for exploration in one segment. B. Slightly arcuate fascial incision $1.5 \mathrm{~cm}$ from the midline. C. Exposure of ligamentun fluvum and facet. D. Setting of Casper retractor.

\subsection{Ligamentum flavum, inferior and superior facet removal}

A transverse cut is made along the lower margin of the upper laminae with a $6-10 \mathrm{~mm}$ osteotome (Fig.2A,B). The bone cut is continued laterally to remove the lower $1 / 3$ of the facet joint. The osteotome is then placed at a $45^{\circ}$ angle and the tip of the superior articular 
process of the lower lamina confirmed. The upper margin of the lower lamina is removed with a narrow osteotome from the base of the spinouts process to the facet. The resection of inferior articular process is safer than that of superior process, because the nerve tissue is protected by superior process. It is safer to break superior articular process just before it is cut completely. If necessary, we can use up-cutting punch, to remove the remnant. The lateral bone strip is removed with a narrow disc rongeur and bone bleeding controled with bone wax. The medial bone strips are then grasped with a disc rongeur and removed with a strong pull. Bleeding from veins in the epidural fat is immediately coagulated bipolarly and packed with Gelfoam and cottonoid patty. The ligamentum flavum is removed from the lower margin and under side of the upper laminae using a curved periosteal elevator (Fig.2C). Removal of medial half of the superior facet exposes $2 \mathrm{~cm}$ or more of the spinal canal lateral to the nerve root (Fig.2D,E), which is filled with epidural fat and veins. These are separated from the lateral margin of the nerve root and dural sac which are retracted medially with a flexible hand held retractor. The resection of inferior articular process is safer than that of superior process, because the nerve tissue is protected by superior process. It is safer to break superior articular process just before it is cut completely. If necessary, we can use upcutting punch, to remove the remnant.

A.

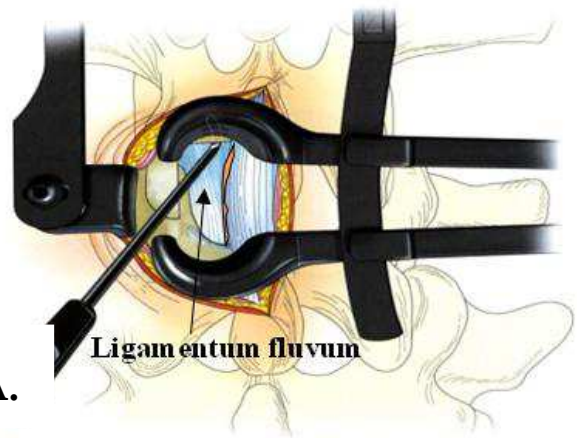

C.

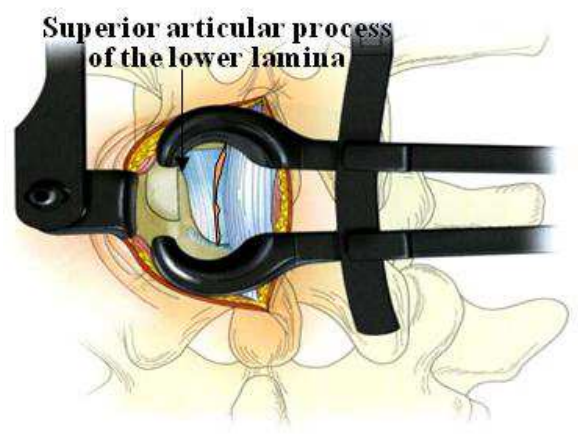

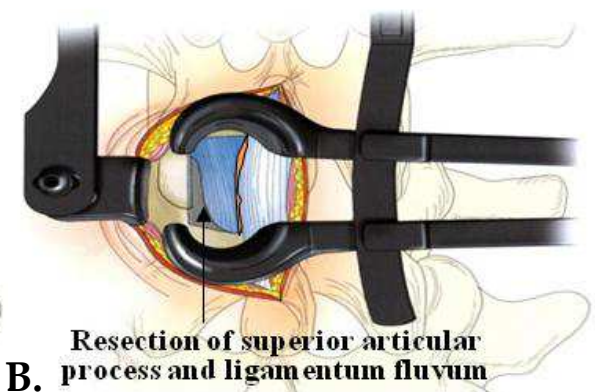

B. process and ligam entum fluvum

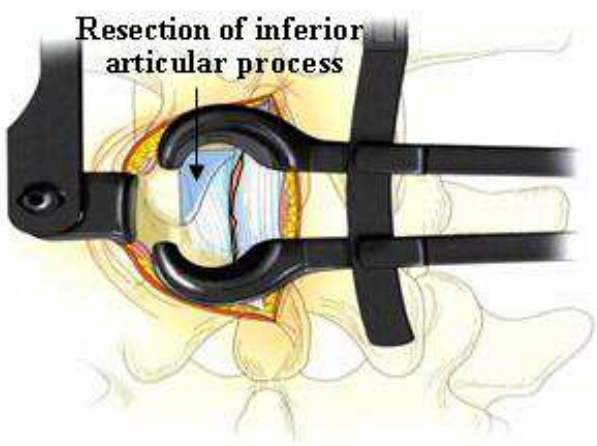

D.

Fig. 2. 

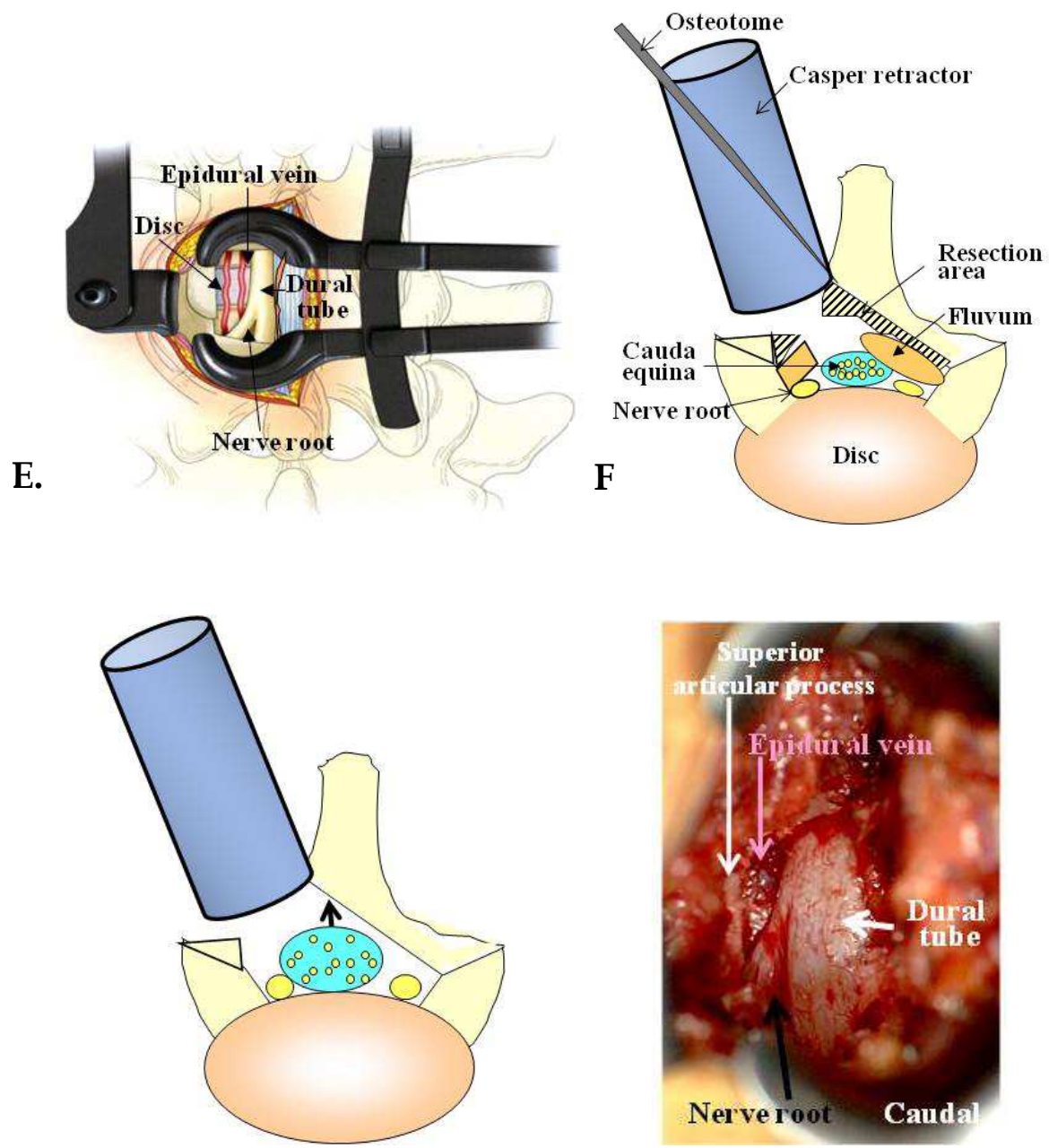

G.

H.

Fig. 2. Removal of the inferior $(A, B)$, superior facet and ligamentum flavum $(C, D)$ and exposure of the nerve tissue and disc surface (E). Then the microscope is tilted, and the cortex is excised from the base of the spinous process to the vertebral arch on the opposite side, exposing the ligamentum flavum on the dorsal aspect of the dura mater $(\mathrm{F}-\mathrm{H})$.

With an operating microscope tilted inwards, the area from the base of the spinouts process to the inner rim of the vertebral arch on the opposite side is resected with an osteotome to semi-circumferentially expose the cauda equina as well as expand the spinal canal (Fig.2F). The ligamentum flavum is identified as a yellow mass under microscope that is loosely contact to the dural sac and the dural sleeve. The ligamentum flavum can completely excised, and adequate decompression of the cauda equine and nerve roots can confirmed under microscope (Fig.2G, H). 


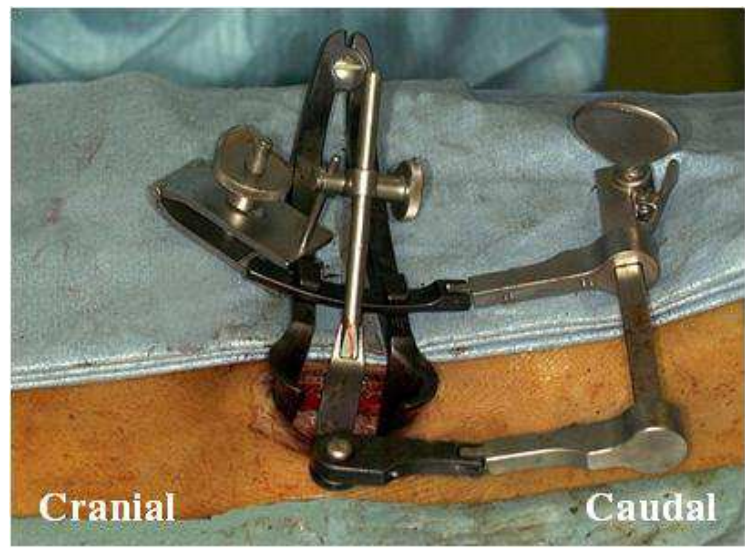

A.
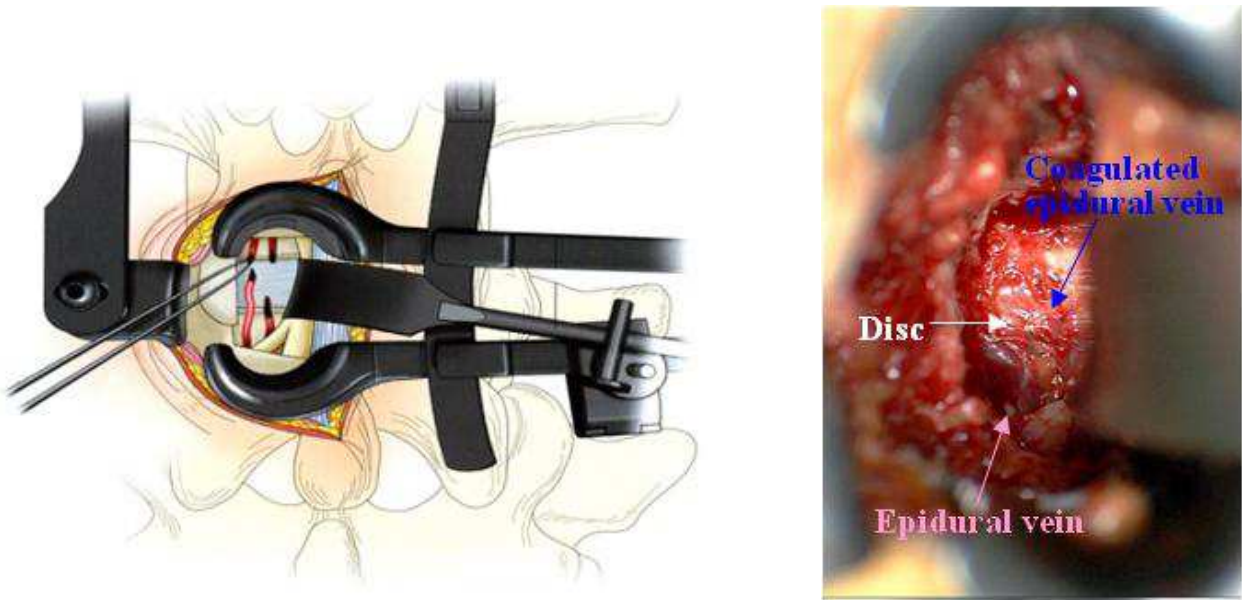

B.

C.

Fig. 3. Setting of a self retaining nerve retractor $(A)$ and treatment of epidural vein on the $\operatorname{disc}(\mathrm{B}, \mathrm{C})$.

A self retaining nerve retractor can be used to fit the exposed nerve root and dural sac. The tip of a self-retaining retractor is placed beneath the nerve root and dural sac, gently retracted to the midline and secured to the clamp on the Casper retractor (Fig.3A). This eliminates strong manual retraction of the nerve root and gives wide exposure of the disc surface. It is very important to control the epidural hemorrhage using electric coagulator and coagulant like cottonoid patty. If it is possible, the epidural veins are immediately coagulated bipolarly before bleeding (Fig.3B,C) and cut with long pointed scissors. This may be a difficult part of the operation, but the disc surface must be widely exposed and completely dry as a bloodless field is essential for the operative attack on the intervertebral disc. 


\subsection{Disc removal and interbody fusion}

The primary goal of this operation is to remove the entire disc and replace it with as much bone as can be inserted into the intervertebral space. A long handled scalpel with pointed blade is used to cut out the posterior half of the disc (Fig.4A). A deep vertical incision is made in the midline beneath the retracted dural sac and nerve root. Then horizontal insicions are made following the margins of the vertebral bodies as far lateral as the exposure will permit, usually beyond the pedicle of the lower vertebra. The incised annulus and disc material is removed enough in this side till the midline using surgical knife, pituitary rongeur, and curette. Next, the posterior edge of the vertebra (end plate) is cut off using an osteotome. An osteotome is hammered at an angle paralleling the disc space and to a depth of around $2 \mathrm{~cm}$ (Fig.4B) and the cartilage end-plates of the lower and upper vertebra removed with a large disc rongeur. This gives a wide opening into the interspace for total removal of the remaining disc tissue. The residual cartilage end plates may be stripped from the vertebral bodies with a long curved osteotome and a ring curette (Fig.4C,D). It is necessary to remove the cartilage end plate and part of the bone plate until enough bleeding comes from the vertebral body. Complete decortication of the surface of the adjacent vertebral bodies is mandatory to obtain blood supply for the interbody bone grafts.

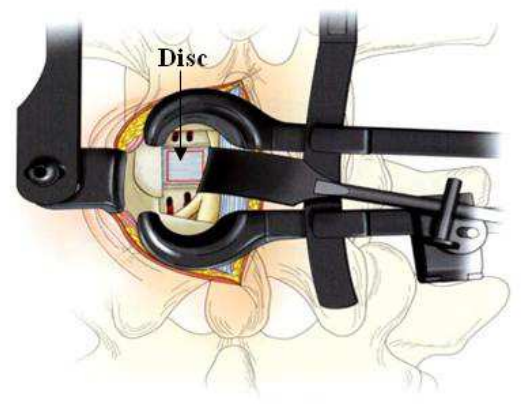

A.

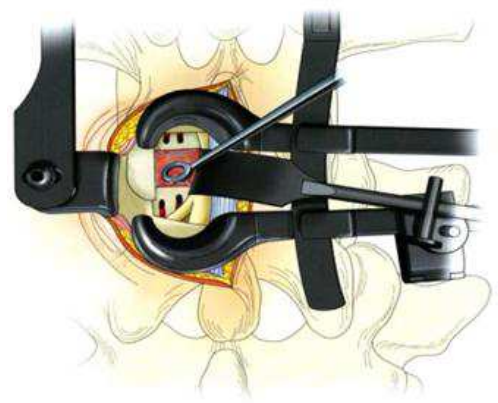

C.

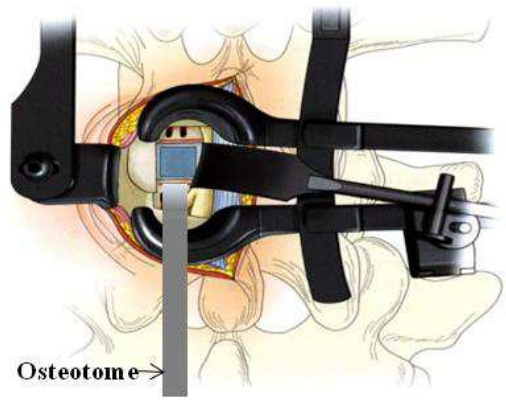

B.

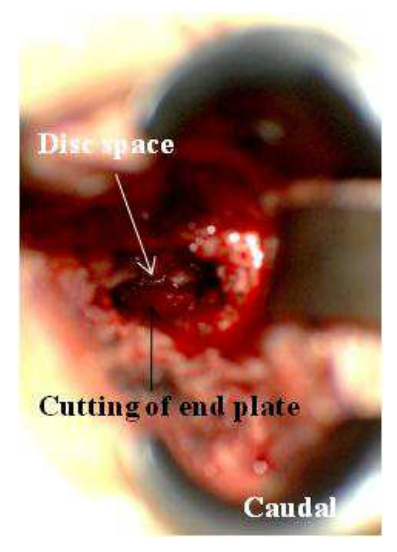

Fig. 4. Cut off end plate $(A, B)$ and disc removal $(C, D)$. 

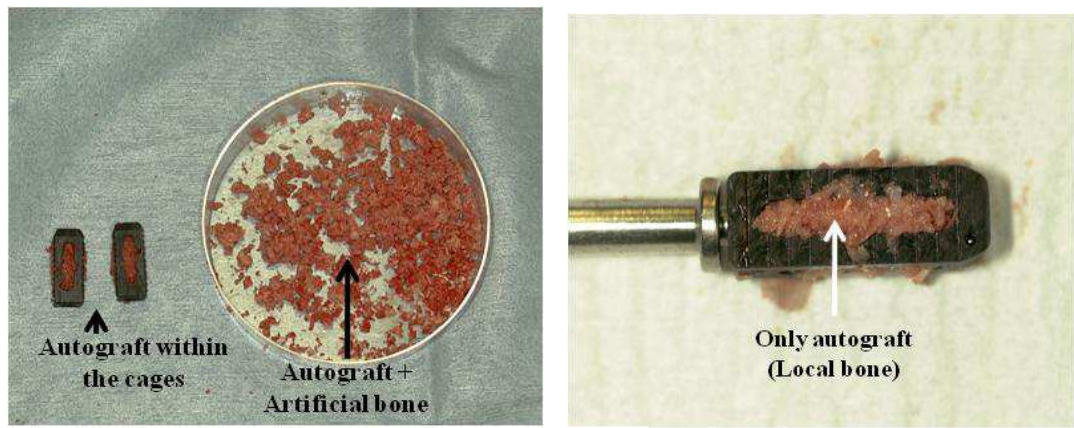

A.

B.
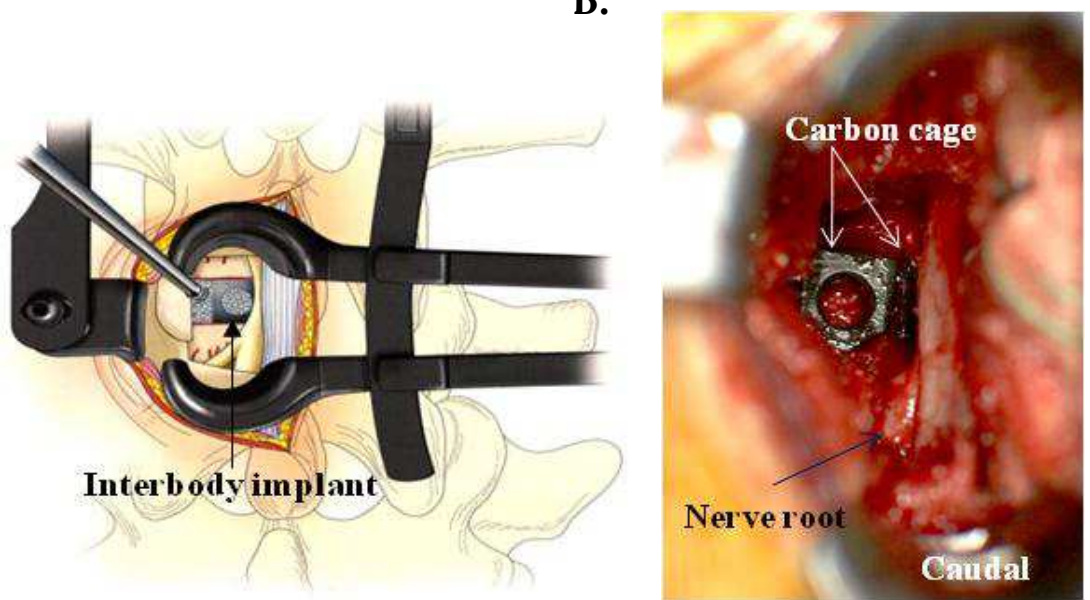

C.

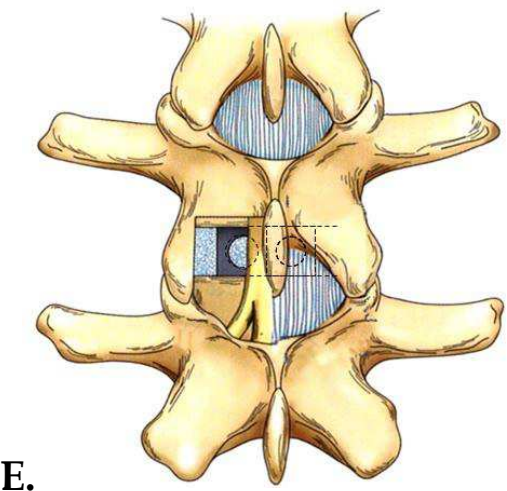

D.

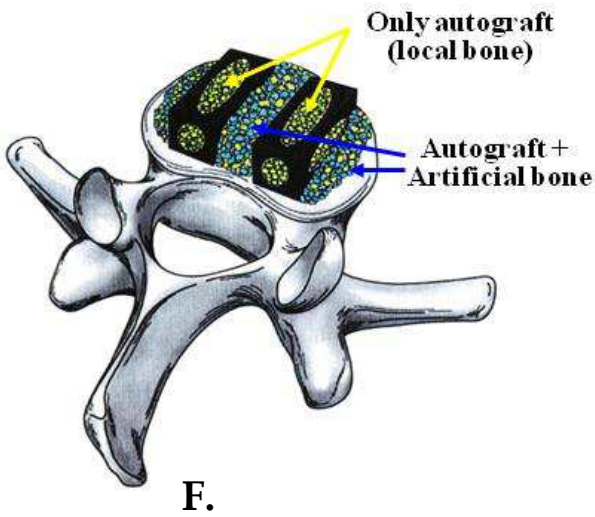

Fig. 5. Interbody fusion using interbody spacers (A-F). 
Bone grafts for the interbody fusion can be obtained from the patient's lamina, inferior and superior facet (local bone tips) and artificial bone (Fig.5A). The graft in an interbody spacer (Branigan carbon cage or polyetheretherketone [PEEK] interbody implant) is only living local bone tips. Around $2 \mathrm{~g}$ of local bone tips can graft in an interbody spacer(Fig.5B). The residual local bone tips (around 2-6 g) and the artificial bone ( $\beta$-tricalcium phosphate $[\beta$ $\mathrm{TCP}]$, around $5 \mathrm{~g}$ ) is mixed and a half of this tips are packed into the anterior disc space. Then, two cages are inserted in the disc space and moved medially using Cloward's puka chisels(Fig.5C-F). Finally, the graft of the residual local bone tips with the artificial bone is inserted laterally(Fig.5D). It is important to spread the intervertebral space enough and to insert and move it. If it is impossible to insert two cages in one side, the same operation is down on the opposite side to insert an another one.

\subsection{Pedicle screw fixation}

Pedicle screws and rods were placed percutaneously (CD Horizon Sextant, Medtronic Sofamor Danek). The placement pf pervutaneous pedicle screws requires the surgeon to be able to accurately interpret antero-posterior and lateral fluoroscopic images to safety insert these devices. The Sextant technique involves placing guidewires through the pedicles passing between 50 and $75 \%$ of the sagittal length of the vertebral body. Standard tubular dilation techniques are performed over the wires. A cannulated tap is placed over them, screw holes are made, and the screws are placed. During percutaneous pedicle screw placement, care must be taken to ensure that the guidewire does not advance through the ventral wall of the vertebral body where it might cause vascular or visceral injury. The screw towers are then coupled together and an arc device with a perforating tip at its distal end is connected to them. The tip is then rotated down to meet the skin. A distal stab incision is then made and the arc is pushed through to make a subcutaneous tract to the aperture of the most proximal screw. A measuring device is then placed on the arc system to

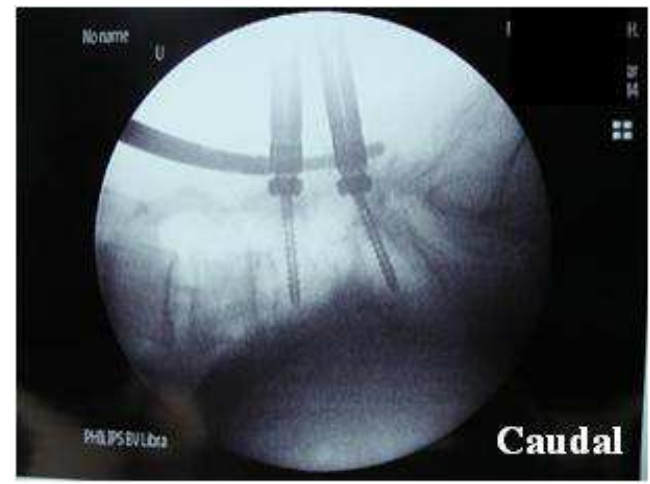

A.

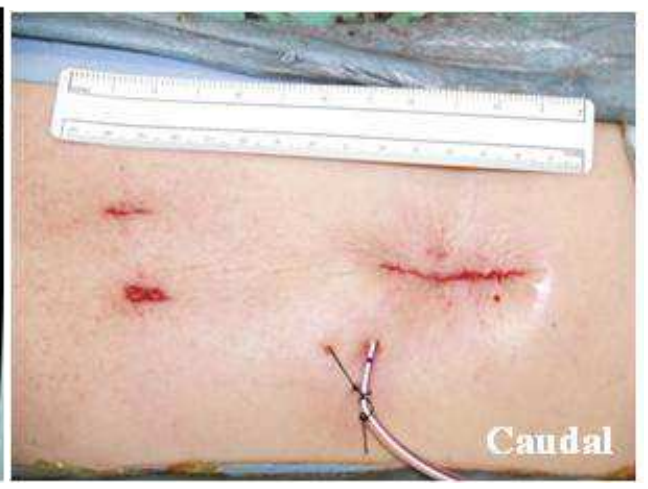

B.

Fig. 6. A. Intraoperative fluoroscopic images demonstrating left L4-5 PLIF procedures with percutaneous pedicle screw, rod and PEEK interbody spacer. B. Final skin wound after operation. Caudal wound made for the Casper retractor and bilateral pedicle screw system. Two $1 \mathrm{~cm}$ wound was needed in the cranial area for rod insertion. 
calculate rod length. The arc is swung back and temporarily withdrawn, and the perforating tip is replaced with the premeasured rod. It is then passed through the priviously made tract that is typically in an ideal vector to engage both screw apertures (Fig.6A). After the position of interbody construct is confirmed under fluoroscope, the pedicle screws are attached to and compressed on the rod, thereby restoring lumbar lordosis while maintaining the restored disc height.

After washing with saline solution, it is possible to hervest subcutaneous fat as a covering and gliding layer for the dura and the root. This remains viable and serves to minimize adhesions formation. A drainage tube is inserted over the grafting fat tissue. After removal of the retractor, the musculature returns spontaneously to the midline. The tendency is further supported by suturing the paraspinally incised fascia. After the subcutaneous tissue are sutured, atraumatic subcuticular skin suture are performed using 5-0 Vicryl (Fig.6B).

\section{Resuls of unilateral micro-PLIF}

\subsection{Patients and methods}

Fifteen patients ( 5 men and 8 women) with Grade I and II degenerative spondylolisthesis (Meyerding, 1932) underwent unilateral micro-PLIF (Table 1). The mean age was 59.3 years (range, 42-76 years old). We used an arc-based system called Sextant (Medtronic) and interbody spacers (Branigun carbon cages or PEEK) were used in all. Presenting symptoms were low back pain with radiculopathy in all patients. All patients had a single-level interbody fusion. Simple PLIF was done at the L4-L5 level in 12 cases and the L3-4 level in one case. Follow-up ranged from 18-40 months (mean, 28.5 months). In these cases, clinical results, operating time, intraoperative blood loss, time for bone union and correction rate of the spondylolisthesis were analysed. Clinical results were evaluated by subjective symptoms (low back pain, 3 points; leg pain and/or tingling, 3 points; gait, 3 points) and clinical signs straight leg raising test, 2 points, sensory disturbance, 2 points, motor disturbance, 2 points) based on the scoring system advocated by the Japanese Orthopaedic Association (JOA) (Table 1). The rate of improvement was calculated by Hirabayashi's method as follows: [(postoperative points - preoperative points)/(normal points preoperative points)] x $100(\%)$.

Percent of slip was measured following Taillard W (1954) (Fig.7). Bone union was evaluated based on criteria by Yamamoto et al (1990). as follows: (1) a diminished line between the bone grafts and vertebrae, (2) a change in the obtuse angle between the bone grafts and vertebrae, and (3) an increase in the trabeculae of the bone grafts.

\subsection{Clinical and radiological outcomes}

In the cases of degenerative spondylolisthesis treated by unilateral micro-PLIF, blood loss was $384.1 \pm 134.7 \mathrm{ml}$ and operating time was $219.6 \pm 31.7$ minutes (Table 2). The pre- and postoperative JOA score is $14.5 \pm 4.0$ points and $24.4 \pm 2.0$ points, respectively (Table 3 ). The improvement rate of JOA score was $67.6 \pm 11.1 \%$. Percent slip before and after operation is $18.3 \pm 5.2 \%$ and $11.5 \pm 4.4 \%$, respectively (Fig.7). The correction of the spondylolisthesis was spontaneously perfomed by prone position on a table withiout the reduction screw. The time for bone union was $7.5 \pm 2.3$ months. All patients presenting with preoperative low 
back pain and sciatica had resolution of symptoms postoperatively and had solid fusions radiographically at lastest follow-up.

\begin{tabular}{|c|c|c|c|c|c|}
\hline I. Subjective Symptoms & (9 points) & \multicolumn{2}{|l|}{ II. Clinical Signs } & & (6 points) \\
\hline \multicolumn{2}{|l|}{ A. Low-back pain } & \multicolumn{4}{|l|}{ A. Straight-leg-raising test } \\
\hline a. None & 3 & \multicolumn{4}{|c|}{ (including tight hamstrings) } \\
\hline b. Occasional mild pain & 2 & \multicolumn{3}{|l|}{ a. Normal } & 2 \\
\hline c. Frequent mild or occasional severe pain & 1 & \multicolumn{3}{|l|}{ b. $30-70^{\circ}$} & 1 \\
\hline d. Frequent or continuous severe pain & 0 & \multicolumn{3}{|l|}{ c. Less than $30^{\circ}$} & 0 \\
\hline B. Leg pain and/or tingling & & \multicolumn{4}{|l|}{ B. Sensory disturbance } \\
\hline a. None & 3 & \multicolumn{3}{|l|}{ a. None } & 2 \\
\hline b. Occasional slight symptom & 2 & \multicolumn{3}{|c|}{ b. Slight disturbance (not subjective) } & 1 \\
\hline c. Frequent slight or occasional severe symptom & 1 & \multicolumn{3}{|l|}{ c. Marked disturbance } & 0 \\
\hline d. Frequent or continuous severe symptom & 0 & \multicolumn{4}{|c|}{ C. Motor disturbance (MMT) } \\
\hline C. Gait & & \multicolumn{3}{|l|}{ a. Normal (Grade 5) } & 2 \\
\hline a. Normal & 3 & \multicolumn{3}{|c|}{ b. Slight weakness (Grade 4) } & 1 \\
\hline \multirow{2}{*}{\multicolumn{2}{|c|}{$\begin{array}{l}\text { b. Able to walk farther than } 500 \mathrm{~m} \text { although } \\
\text { resulting in pain, tingling, and/or muscle weakness }\end{array}$}} & \multicolumn{3}{|c|}{ c. Marked weakness (Grade $3-0$ ) } & 0 \\
\hline & & \multicolumn{4}{|c|}{ III. Restriction of Activities of Daily Living (ADL) (14 Points) } \\
\hline \multirow{2}{*}{$\begin{array}{l}\text { c. Unable to walk farther than } 500 \mathrm{~m} \text { owing } \\
\text { to leg pain, tingling, and/or muscle weakness }\end{array}$} & \multirow[t]{2}{*}{1} & a. Turning over while & 0 & 1 & 2 \\
\hline & & b. Standing & 0 & 1 & 2 \\
\hline \multirow{2}{*}{$\begin{array}{l}\text { d. Unable to walk farther than } 100 \mathrm{~m} \text { because } \\
\text { of leg pain, tingling, and/or muscle weakness }\end{array}$} & \multirow[t]{2}{*}{0} & c. Washing & 0 & 1 & 2 \\
\hline & & d. Leaning forward & 0 & 1 & 2 \\
\hline IV. Urinary bladder function & (-6 Points) & e. Sitting (about 1 hour) & 0 & 1 & 2 \\
\hline a. Normal & 0 & f. Lifting or holding & 0 & 1 & 2 \\
\hline b. Mild dysuria & -3 & heavy objects & 0 & 1 & 2 \\
\hline c. Severe dysuria (incontinence, urinary retention) & -6 & g. Walking & 0 & 1 & 2 \\
\hline
\end{tabular}

Table 1. Score rating system of the Japanese orthopaedic association (JOA score).

\begin{tabular}{cccccccccc}
$\begin{array}{c}\text { Case } \\
\text { No. }\end{array}$ & Age & Sex & $\begin{array}{c}\text { Follow-up } \\
\text { Period }\end{array}$ & $\begin{array}{c}\text { Operated } \\
\text { Levels }\end{array}$ & $\begin{array}{c}\text { Interbody } \\
\text { Spacer }\end{array}$ & $\begin{array}{c}\text { Autograft(g) } \\
\text { [Local bone] }\end{array}$ & $\begin{array}{c}\text { Artificial } \\
\text { Bone(g) }\end{array}$ & $\begin{array}{c}\text { Blood } \\
\text { Loss(g) }\end{array}$ & $\begin{array}{c}\text { Operation } \\
\text { Time(min.) }\end{array}$ \\
\hline 1 & 70 & F & 40 & L4-5 & CC & 5 & 6 & 460 & 331 \\
2 & 44 & F & 39 & L4-5 & CC & 7 & 5 & 300 & 235 \\
3 & 65 & F & 38 & L4-5 & PEEK & 6 & 5 & 360 & 272 \\
4 & 55 & F & 38 & L3-4 & PEEK & 7 & 5 & 460 & 195 \\
5 & 71 & M & 35 & L4-5 & PEEK & 8 & 4 & 420 & 250 \\
6 & 76 & M & 34 & L4-5 & PEEK & 6 & 5 & 515 & 210 \\
7 & 44 & F & 30 & L4-5 & PEEK & 5 & 5 & 330 & 165 \\
8 & 62 & M & 30 & L4-5 & PEEK & 6 & 5 & 250 & 235 \\
9 & 53 & F & 28 & L4-5 & PEEK & 6 & 5 & 270 & 255 \\
10 & 57 & M & 24 & L4-5 & PEEK & 8 & 4 & 280 & 220 \\
11 & 53 & F & 20 & L4-5 & PEEK & 4 & 6 & 550 & 190 \\
12 & 47 & F & 18 & L4-5 & PEEK & 8 & 5 & 190 & 222 \\
13 & 69 & M & 18 & L4-5 & PEEK & 6 & 5 & 600 & 202 \\
\hline Average 59.3 & & 28.5 & & & 6.4 & 4.9 & 384.1 & 219.6 \\
S.E.M. & 10.2 & & 7.6 & & & 1.3 & 0.5 & 134.7 & 31.7
\end{tabular}

CC: Branigan carbon cage, PEEK: polyetheretherketone interbody implant)

$\beta$-TCP: $\beta$-tricalcium phosphate

Table 2. Summary of patients treated by unilateral micro-PLIF. 


\begin{tabular}{ccccccc}
$\begin{array}{c}\text { Case } \\
\text { No. }\end{array}$ & $\begin{array}{c}\text { JOA } \\
\text { score }\end{array}$ & $\begin{array}{c}\text { JOA } \\
\text { score }\end{array}$ & $\begin{array}{c}\text { Rate of } \\
\text { Improvement }\end{array}$ & $\begin{array}{c}\text { \%-Slip } \\
\text { (Pre-ope) }\end{array}$ & $\begin{array}{c}\text { \%-Slip } \\
\text { (Post- }\end{array}$ & $\begin{array}{c}\text { Periods for } \\
\text { Bone Union }\end{array}$ \\
\hline 1 & 9 & 23 & 70.0 & 30.0 & 23.3 & 12.0 \\
2 & 15 & 25 & 71.4 & 24.0 & 9.5 & 6.0 \\
3 & 18 & 25 & 63.6 & 29.6 & 8.7 & 6.0 \\
4 & 17 & 25 & 66.7 & 17.4 & 13.0 & 6.0 \\
5 & 13 & 22 & 56.3 & 20.0 & 16.0 & 12.0 \\
6 & 15 & 23 & 57.1 & 21.7 & 19.2 & 9.0 \\
7 & 9 & 22 & 65.0 & 10.0 & 8.0 & 6.0 \\
8 & 10 & 22 & 63.2 & 15.4 & 11.5 & 9.0 \\
9 & 19 & 27 & 80.0 & 16.7 & 8.7 & 5.0 \\
10 & 21 & 26 & 62.5 & 13.0 & 4.3 & 5.0 \\
11 & 15 & 23 & 57.1 & 20.8 & 16.7 & 9.0 \\
12 & 13 & 27 & 87.5 & 15.8 & 10.8 & 6.0 \\
13 & 10 & 26 & 84.2 & 20.8 & 9.5 & 9.0 \\
\hline Average & 14.5 & 24.4 & 67.6 & 18.3 & 11.5 & 7.5 \\
S.E.M. & 4.0 & 2.0 & 11.1 & 5.2 & 4.4 & 2.3
\end{tabular}

Table 3. Clinical and radiological outcome before and after surgery.

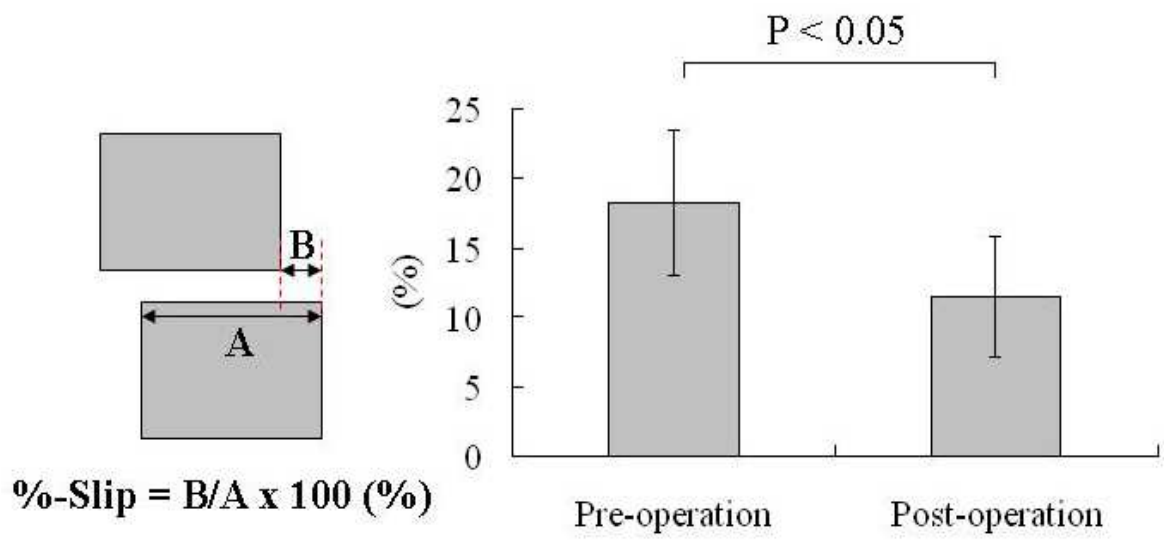

Fig. 7. Measurement of slip percent before and after surgery.

\section{Case report}

A 65-year-old woman (Case 3) presented with a long history of severe low back pain and left leg pain. This patient had numbness and hypesthesia of L5 root area on her left leg. Straight leg raising test is negative on both sides. Leg muscles are powerful. JOA score was 18 points. Preoperative plain films showed evidence of degenerative Grade II spondylolisthesis at L4-L5 (Fig.8A-C). She failed all attempts at nonoperative therapy, including nonsteroid anti-inflammatory drugs, epidural steroid injections and physical therapy. In the preoperative imaging study, extension and flexion plain film revealed a mobile spondylolisthesis at L4-L5. MR imaging showed the circumferential cauda equina and nerve root compression at L4-L5 disc level (Fig.9A,B). 

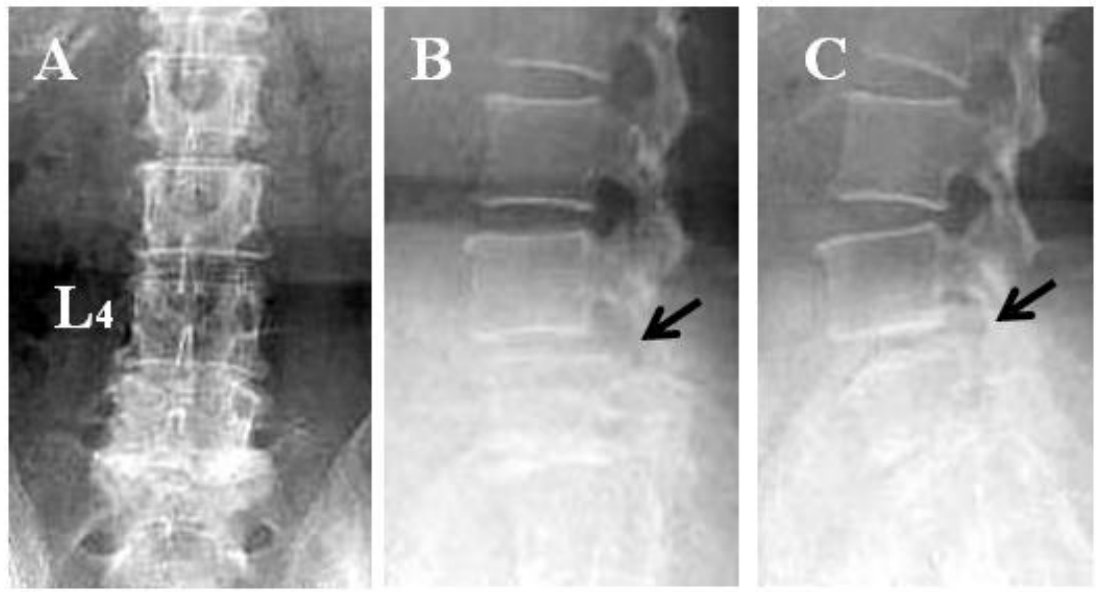

Fig. 8. Pre-operative anteroposterior (A) and lateral (B, flexion position, C, extension position) plain radiographs. Flexion and extension plain film revealed a mobile spondylolisthesis (arrows).
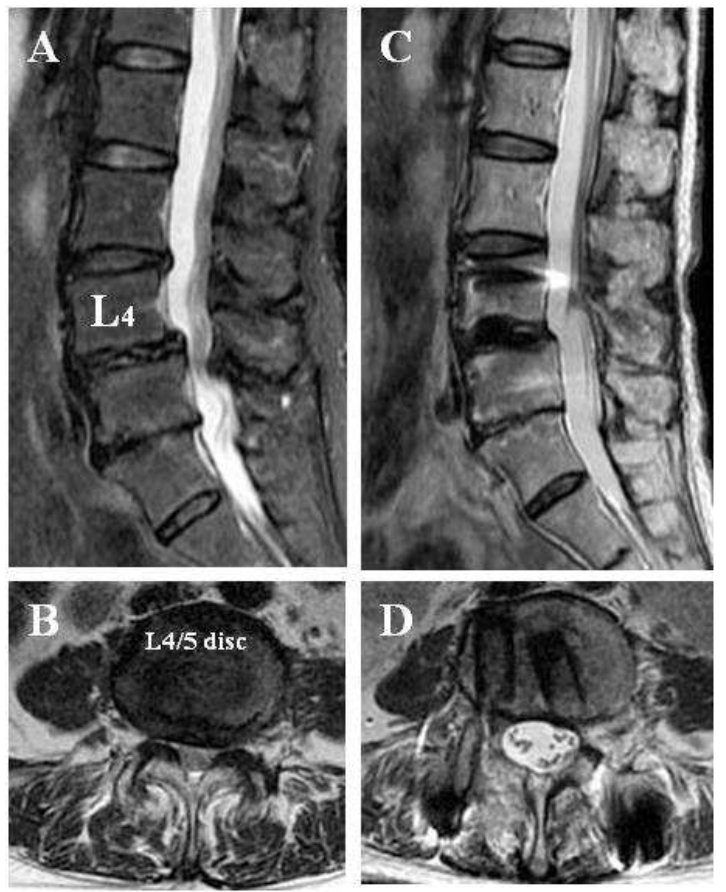

Fig. 9. Pre- $(A, B)$ and Post- $(C, D)$ operative T2 weighted MR imaging. A,C. Sagittal view, B,D. Axial view. 
Preoperative MR imaging demonstrated mild central canal stenosis secondary to degenerative spondylolisthesis L4-L5 (A,B). Postoperative MR imaging did not show cauda equina compression 2 year after surgery $(\mathrm{C}, \mathrm{D})$. Restration of disc hight and lordosis also demonstrated .
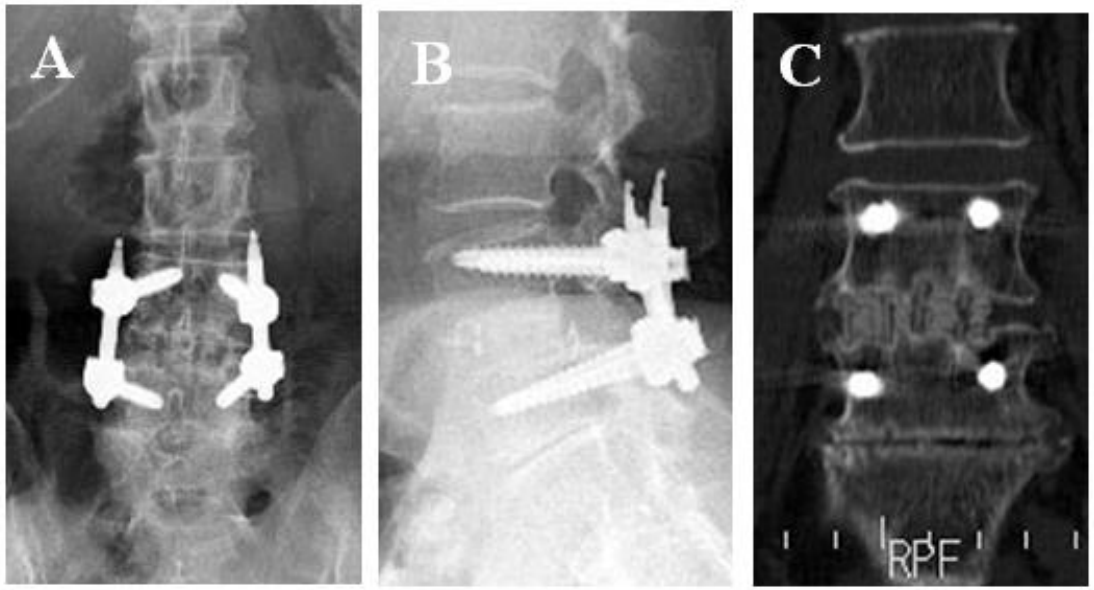

Fig. 10. Post-operative plain radiographs [anteroposterior view (A), lateral view(B)] and coronal reformatted CT (C).

This patient underwent a minimally invasive PLIF via a Casper retractor placed from a leftsided approach. The interbody fusion was supplemented with percutaneous pedicle screw and rods. The patient's surgery was uneventful. She was discharged on postoperative day 14 and returned to her previous job in 3 months after this operation. After 24 months of follow-up, she had no evidence of low back pain but slightly numbness requiring no medication persisted. The X-ray showed the bone union of PLIF without collapse at 2 years after operation. Frontal view (Fig.10A) and coronal CT scan (Fig.10C) showed bone union in PEEK interbody spacers. Lateral view showed solid fusion (Fig.10B). MR imaging did not show cauda equine compression (Fig9C,D).

\section{Complications of minimally invasive arthrodesis procedure}

The goal of lumbar interbody fusion is to stabilize the spinal segment and decompress the neural elements. PLIF can completely remove the pathological focus by the naked-eye or using an operating microscope. However, the PLIF requires significant retraction on the dural sac and nerve roots. As a result, it is associated with higher risks of cerebrospinal fluid leakage, dysesthetic nerve root pain syndrome, nerve root injury, and epidural fibrosis (Lin, 1985, Fritzell, et al., 2002, Scaduto, et al., 2003). These complications can be avoided by microscope visualization of the working space during surgery.

Transforaminal lumbar interbody fusion (TILF) is originally described by Blume and Rojas (1981) and Harms and Rolinger (1982). The TILF approach was popularized by Harms et al (1997). TILF was reported to be an effective surgical technique for the treatment of various degenerative lumbar diseases because it allows lateral access to the neural canal. This 
incision is two fingerbreadths off of the midline and allows for a paraspinal muscle splitting (Wiltse) approach to be performed (Wiltse \& Spencer, 1988). The procedure involves less retraction of the dural sac and nerve roots resulting in low complication rate, and produces clinical outcomes and fusion rates similar to those of other techniques. However, the ideal indication for a TILF is a grade 1 or grade 2 spondylolisthesis without neurologic deficit or with a deficit on one side only (Moskowitz, 2002). This approach cannot completely remove the pathological focus with central canal stenosis. Although offering certain advantages, minimally invasive arthrodesis procedure has several limitations and potential complications. There is a learning curve associated with the development of technical skills necessary to perform these procedure.

\section{Conclusions}

Minimal invasive spinal surgery is an expanding technique and percutaneous pedicle screws are often used to minimize muscle injuries. However, there is no proof that spinal outcomes are better with minimally invasive spinal surgery than with conventional spinal surgery, which remains the gold standard against which new techniqus should be evaluated. The PLIF procedure has come into a fair amount of disfavor because of perceived and actual complications related to the procedure. These complication include bleeding, dural laceration, nerve root injuries, graft migration and pseudarthrosis. High fusion rates with good clinical outcomes can be achieved with few complications using microscope and minimal invasive technique. Our clinical experience using the microscope has showed excellent visualization, appropriate safety control, and low complication rate. Skilled surgeons familiar with the technique, anatomy, and instrumentation involved in minimally invasive approaches can achieve good-to-excellent clinical results..

\section{References}

Blume,H.G. \& Rojas, C.H. (1981). Unilateral lumbar interbody fusion (posterior approach) utilizing dowel graft. J Neurol Ortop Surg, 2, 171-175.

Brantigan, J.W.\& Steffee, A.D. (1993). A carbon fiber implant to aid interbody lumbar fusion two-year clinical results in the first 26 patients. Spine, 18, 2106-2117.

Bridwel, K.H.; Sedgewick, T.A.; O'Brien, M.F., et al. (1993). The role of fusion and instrumentation in the treatment of degenerative spondylolisthesis with spinal stenosis. J Spinal Disord, 6,461-472

Cloward, R.B. (1952). The treatment of ruptured lumbar intervertebral disc by vertebral body fusion. III. Methods and use of banked bone. Ann Surg, 136, 987-992

Cloward, R.B. (1953). The treatment of ruptured lumbar intervertebra1discs by vertebral body fusion. I. Indications, operative technique, after care. J Neurosurg,10, 154-168.

Cloward, R.B. (1981). Spondylolisthesis, treatment by laminectomy and PLIF. Clin Orthop. $154,74-82$.

Cloward, R.B. (1985). The treatment of ruptured lumbar intervertebral disk by vertebral body fusion. Clin Orthop, 193, 5-154.

Faubert, C. \& Caspar, W. (1991). Lumbar percxtaneous discectomy. Initial experience in 28 cases. Neuroradiology, 33, 407-410.

Fischgrund, J.S.; MacKay, M.; Herkowitz, H.N., et al. (1997). Degenerative lumbar spondylolisthesis with spinal stenosis: A prospective, randomized study 
comparing decompressive and arthrodesis with and without spinal instrumentation. Spine, 22, 2807-2812.

Foley KT, Gupta SK, Justis JR, et al. (2001). Percutaneous pedicle screw fixation of the lumbar spine. Neurosurg Focus, 10, E10

Fritzell, P.; Hagg, O.; Wessberg, P., et al. (2002). Chronic low back pain and fusion. A comparison of three surgical techniques: a prospective multicenter randomized study from the Swedish Lumbar Spine Group. Spine, 27, 1131-1141.

Harms, J. \& Rolinger, H. (1982). A one-stage procedure in operative treatment of spondylolisthesis: dorsal traction-reposition and anterior fusion. Z Orthop Ihre Grenzgeb, 120, 343-347

Harms, J.; Jeszenszky, D.; Stolze, D., et al. (1997). True spondylolisthesis reduction and more segmental fusion in spondylolisyjesis. In: The Textbook of Spinal Surgery. 2nd Ed. Philadelphia: lipponcott-raven, 1337-1347.

Lin,P.M. (1985). Posterior lumbar interbody fusion technique: complications and pitfalls. Clin Orthop, 193, 90-102.

Magerl, F. (1982) External skeletal fixation of the lower thoracic and lumbar spine, in Uhthoff, H.K. \& Stahl, E. (eds.): Current Concepts of External Fixation of Fractures. New York: Springer-Verlag, pp 353-366.

Meyerding, H.W. (1932). Spondylolisthesis: surgical treatment and results. Surg Gynecol Obstet 54:371-377.

Moskowitz, A. (2002). Transforaminal lumbar interbody fusion. Orthop Clin North Am, 33, 359-366.

Park, P. \& Foley, K.T. (2008) Minimally invasive transforaminal interbody fusion with reduction of spondylolisthesis: technique and outcomes after a minimum of 2 years' follow-up. Neurosurg Focus, 25,E16.

Scaduto, A.A.; Gamradt, S.C.; Yu,W.D., et al. (2003). Perioperative complications of tgreaded cylindrical lumbar interbody fusion devices: anterior versus posterior approach. $J$ Spinal Disord Tech, 16, 502-507.

Takeno, K., Kobayashi, S., Miyazaki, S., et al. (2010). Microsurgical excision of hematoma of the lumbar ligamentum flavum. Joint Bone Spine, 77, 351-354.

Taillard, W. (1954). Le spondylolisthesis chez $\mathrm{l}^{\prime}$ enfant et l'adolescent (Etude de 50 cas). Acta Orthop Scand,24, 115-144.

Wiltse, L.L. \& Spencer, C.W. (1988). New uses and refinements of the paraspinal approach to the lumbar spine. Spine, 13, 696-706.

Yamamoto, M.; Kadowaki, T.; Ota, N. et al. (1990). PLIF for lumbar degenerative spondylolisthesis. Rinsho Seikeigeka, 25, 487-494.

Young, S.; Veerapen, R.; O'Laoire, S.A.. (1988.): Relief of lumbar canal stenosis using multilevel subarticular fenestrations as an alternative to wide laminectomy: preliminary report.. Neurosurgery, 23, 628-633.

Yvon, H.A.; Garfin, S.R.; Dickman, C.A. et al. (1994). A historical comfort study of pedicle screw fixation in thoracic, lumbar and sacral spinal fusions. Spine, 19(Suppl), 2279S2296S.

Zdeblick, T.A. (1993). A prospective, randomized study of lumbar fusion. Spine, 18, 983-991. 


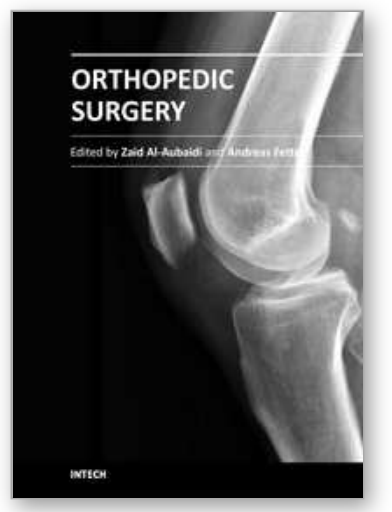

\author{
Orthopedic Surgery \\ Edited by Dr Zaid Al-Aubaidi
}

ISBN 978-953-51-0231-1

Hard cover, 220 pages

Publisher InTech

Published online 09, March, 2012

Published in print edition March, 2012

Orthopaedic surgery is the widest and the strongest growing surgical specialty. It is clear, that the process of improving treatments and patients care, requires knowledge, and this requires access to studies, expert opinion and books. Unfortunately, the access to this knowledge is being materialized. As we believe that access to the medical knowledge should be reachable to everyone free of charge, this book was generated to cover the orthopaedic aspect. It will provide the reader with a mix of basic, but as well highly specialized knowledge. In the process of editing this book, my wife Jurgita has been, as usual, the most supportive person. I would like to thank her for being in my life. I would like to thank Mr. Greblo, the Publishing Process Manager, for all his help and last but not least thanks to our readers, as without them this book would have no meaning.

\title{
How to reference
}

In order to correctly reference this scholarly work, feel free to copy and paste the following:

Shigeru Kobayashi (2012). Unilateral Minimally Invasive Posterior Lumbar Interbody Fusion (Unilateral MicroPLIF) for Degenerative Spondylolisthesis: Surgical Technique, Orthopedic Surgery, Dr Zaid Al-Aubaidi (Ed.), ISBN: 978-953-51-0231-1, InTech, Available from: http://www.intechopen.com/books/orthopedicsurgery/minimally-invasive-posterior-lumbar-interbody-fusion-plif-for-degenerative-spondylolisthesis-surgica

\section{INTECH}

open science | open minds

\author{
InTech Europe \\ University Campus STeP Ri \\ Slavka Krautzeka 83/A \\ 51000 Rijeka, Croatia \\ Phone: +385 (51) 770447 \\ Fax: +385 (51) 686166 \\ www.intechopen.com
}

\author{
InTech China \\ Unit 405, Office Block, Hotel Equatorial Shanghai \\ No.65, Yan An Road (West), Shanghai, 200040, China \\ 中国上海市延安西路65号上海国际贵都大饭店办公楼405单元 \\ Phone: +86-21-62489820 \\ Fax: +86-21-62489821
}


(C) 2012 The Author(s). Licensee IntechOpen. This is an open access article distributed under the terms of the Creative Commons Attribution 3.0 License, which permits unrestricted use, distribution, and reproduction in any medium, provided the original work is properly cited. 